\title{
RELAÇÕES ENTRE O ESVAZIAMENTO DA FUNÇÃO SIMBÓLICA E $O$ DESINTERESSE DISCENTE PELAS ROTINAS ESCOLARES
}

\author{
Marlon Dantas Trevisan ${ }^{1}$
}

\begin{abstract}
Resumo:
O trabalho reflete sobre as causas históricas da crise escolar, destacando dentre elas a degeneração simbólica relativa aos conteúdos instrucionais. Procura-se demonstrar que tal aspecto semiótico apresenta relação com o desinteresse discente pelo aprendizado, comprometendo os resultados e mesmo a função social da escola. Em termos metodológicos, o escrito caracteriza-se como redescrição (Rorty, 1995). Para a análise histórica, perfilaram-se autores como Patto (1999) e Romanelli (2010), dentre outros; para as reflexões sobre linguagem, recorreu-se à filosofia de Dewey (1958) e Peirce (1977). Na conclusão, apontam-se as relações da degeneração simbólica com as causas históricas do insucesso da instituição educativa, propondo-se ao docente uma reflexão sobre os códigos pedagógicos praticados, com vistas ao resgate das linguagens, buscando-se novos significados para as rotinas escolares.
\end{abstract}

Palavras-chave: Insucesso escolar. Desinteresse. Símbolo. Conteúdos instrucionais.

\footnotetext{
1 Doutor em Educação pela UNESP/Marília/SP, semioticista, docente do Dept ${ }^{\circ}$ de Educação do Instituto de Ciências Humanas e Sociais /ICHS, da Universidade Federal do Mato Grosso/UFMT, Câmpus de Rondonópolis, bem como do Programa de Pós-Graduação em Educação/PPGEdu/ICHS, Linha de Pesquisa: "Linguagem, Cultura e Construção de Conhecimento”, membro do Grupo de Pesquisa ALFALE - Alfabetização e Letramento Escolar.

E-mail: marloneanela@uol.com.br
} 


\title{
THE RELATIONSHIP BETWEEN THE DEPLETION OF SYMBOLIC FUNCTION AND STUDENT'S LACK OF INTEREST IN SCHOOL ROUTINES
}

\author{
Marlon Dantas Trevisan
}

\begin{abstract}
:
This article reflects on the historical causes of the educational crisis, highlighting among them the symbolic degeneration related to the instructional material. It aims to demonstrate that this semiotic aspect is related to the students' lack of interest in learning, which threatens results and even the school's social function. In methodological terms, this work is characterized as redescription (Rorty, 1995). For the historical analysis, authors such as Patto (1999) and Romanelli (2010), among others, were profiled; for the reflections on language, the philosophy of Dewey (1958) and Peirce (1977) was used. In conclusion, this work points to the relationship between symbolic degeneration and the historical causes of failure of the educational institution and suggests to educators a reflection on the pedagogical codes practiced, with the objective of rescuing languages and searching for new meanings for school routines.
\end{abstract}

Keywords: Academic Failure. Disinterest. Symbolisml. Instructional material. 


\section{Introdução}

Este texto constitui uma reflexão sobre linguagem e comunicação no contexto escolar, de modo a buscarmos novas respostas para o insucesso da educação pública. Afirmamos que o desinteresse discente pela aprendizagem insere-se na complexa cadeia causal que caracteriza o naufrágio das instituições educativas. Procuramos destarte responder à questão relativa a quais aspectos sociopedagógicos e semióticos estariam implicados em tal indiferença. Nossos objetivos específicos dizem respeito a enumerar historicamente as hipóteses explicativas mais conhecidas para tal flagelo; descrever conceitualmente o símbolo e sua relação com os conteúdos didáticos; explicar de que modo o esvaziamento da função simbólica nos discursos pedagógicos contribuiu para o desinteresse dos educandos, desde a antiguidade greco-latina até os dias atuais. Faremos um percurso que busca uma interface entre a História da Educação, a Sociologia e a Filosofia da Linguagem, tendo em vista examinarmos aspectos diacrônicos da crise no Brasil, em escala secular. Por ser um estudo sobre educação, sentimo-nos à vontade ao aproximar tais ciências, dada a complexidade de tal objeto. Não por acaso, Libâneo (2012) defende a parceria de várias delas para a melhor compreensão do fenômeno educacional.

Este escrito apresenta um pluralismo teórico contíguo a tempos mais democráticos. Cremos na importância de superarmos antigos tabus relativos à pesquisa, tais como a exigência de se alinharem apenas autores de uma mesma filiação ideológica para que o texto possa apresentar coerência. É bem verdade que defendemos também o respeito à integridade de suas respectivas ideias, em que pese certos fundamentalismos não o crerem possível quando se busca a pluralidade. Buscamos um espinhoso lugar em que esses diálogos sejam possíveis, certos de que há pontos de contato entre sistemas cujos contextos políticos os tenham afastado. Como exemplo de conexões de tal ordem, lembramos a notória influência de Hegel, tanto sobre Marx (QUINTANEIRO; BARBOSA; OLIVEIRA, 2002), quanto sobre Dewey (CUNHA, 2010). A perspectiva estética, analítica e também metodológica da redescrição, tal como a propõe Rorty (1995), autoriza-nos a tais aproximações. Pretendemos redescrever, contingencialmente, o que nos tem passado, buscando os sentidos produzidos pela linguagem nos contextos da experiência, não uma essência dos seres / objetos ou os velhos púlpitos da epistemologia, onde se propalavam verdades fixas, mas uma narrativa sem pretensões de universalidade ou supra-humanidade (FAVERO, 2006). Nossa rotina de interpretação dos escritos, articulando conceitos, dados, dentre outros procedimentos bibliográficos, busca uma enunciação falível, atenta ao melhor entendimento.

\section{Origens (hipóteses) históricas da crise escolar}

De todos os problemas relativos à ação governamental brasileira, a educação é a 
Relações entre o esvaziamento da função simbólica e o desinteresse discente pelas rotinas escolares

que mais nos envergonha, o mais trágico dos percursos (LIBÂNEO; OLIVEIRA; TOSCHI, 2010). A cultura do fracasso escolar sempre fora uma realidade inegável, alimentando-o, reproduzindo-o, legitimando sua prática, perpetuando preconceitos de raça, gênero, classe social, sendo a avaliação, em suas diversas expressões, um operador central em tal prática, cujo ápice se configuraria com a retenção do estudante, senão sua expulsão. Não constitui intento deste trabalho discutir tal expediente pedagógico, pelos limites do texto, o que também nos levaria a discutir a escola ciclada, implantada. nos anos de 1980, em escolas estaduais paulistas e mineiras, contraponto ao sistema seriado, que levava adiante reprovações em grande escala. Apenas ressaltamos que a pedagogia do exame, tal como a denomina Luckesi (2008), constitui-se em lamentável indicador de quanto um projeto pedagógico pode naufragar: para que se mantenha o interesse e o controle dos alunos, resta ao educador ameaçá-los com a avaliação e todas as consequências que ela pode trazer para a vida discente. Vemos no expediente avaliativo um operador de círculo vicioso: constitui-se consequência do fracasso pedagógico, assim como passa a ser uma causa deste, quando obriga os alunos a apenas “estudarem para a prova”, não raro reduzindo a aprendizagem à simples memorização.

Se examinarmos a história da escolaridade, em especial a Educação Básica, veremos que ela sempre legitimou e consolidou a condição de classe dos que a frequentam. A permanência no sistema determina-se pela condição social (FREITAS, 1995). Aqui temos explícita a relação entre escola e organização social. O Estado, terceiro correlato da tríade, é o financiador educacional. Desde o Brasil Colônia, temos este arranjo trino.

Romanelli (2010) descreve-nos, acuradamente, todo o trajeto que culmina, ainda hoje, com o cenário com que nos deparamos: escolas particulares com proposta propedêutica (26,5\% de todo o contingente estudantil, segundo o Censo Escolar da Educação Básica de 2016, realizado pelo Inep), voltadas ao sucesso nos vestibulares e a rede pública de Educação Básica (73,5\%) precisando de uma política de cotas nas universidades, dentre outras ações reparadoras, para inserir seus egressos nos cursos mais disputados.

Nas últimas décadas, apesar de ter havido um aumento de matrículas dos alunos(as) provenientes das camadas populares, ainda há um triste contingente de crianças e adolescentes fora da escola. Com relação à faixa etária entre 4 e 17 anos (período correspondente à Educação Básica), tínhamos 2,48 milhões, em 2016, segundo dados da Pesquisa Nacional por Amostra de Domicílios (PNAD). Os jovens com idade entre 15 a 17 anos à margem das instituições escolares somavam 1,54 milhão (17,4\%). Há que se reconhecer, entre 2005 e 2015, o avanço no atendimento ao Ensino Médio, embora o mais tímido de todas as modalidades, com um aumento nas matrículas de $78,8 \%$ para $82,6 \%$.

As taxas de analfabetismo têm caído gradativamente no país. Entre 2001 e 2014, vimos uma redução de 4,3 \%, valor correspondente a 2,5 milhões de analfabetos, 
segundo a Pnad (IBGE, 2014). O total de analfabetos reduziu-se de 11,5\%, em 2004, para 7,2\%, em 2016. Apesar de positivos, os números não escondem o fato de o Brasil ocupar o triste oitavo lugar no mundo com relação à população analfabeta: são ainda cerca de 11,8 milhões de pessoas (IBGE, 2017).

Vale-nos ponderar que esses índices afastam-se bastante do que prescrevia a Lei $\mathrm{n}^{\circ}$ 10.172 / 2001 - Plano Nacional de Educação 2001-2010 (primeiro PNE a se tornar lei), cuja meta consistia na redução para $6,5 \%$ da taxa de analfabetismo da população maior de 15 anos, até 2015, como também reduzindo o analfabetismo funcional pela metade (BRASIL, 2001). Esse contexto de mesma gravidade diz respeito a indivíduos, com 15 anos ou mais, cuja escolaridade contaria com menos de 4 anos. Tivemos, com relação a tal problema brasileiro, uma diminuição geral de 21,9\%, em 2001, para 17,6\%, em 2014. Na Região Norte, observou-se o maior declínio, de 21,6\% para 20,4\%. Tendo recuado timidamente, os índices da Região Nordeste são os mais altos: 27,7\% em 2013 e 27,1\% em 2014. Os dados mais baixos são oriundos das Regiões Sudeste, 12,7\%, e Sul, 13,8\%. Conforme o levantamento Education for All Global Monitoring Report, 38\% dos analfabetos latino-americanos, naquela ocasião, eram brasileiros (UNESCO, 2015). Segundo Libâneo (2010), 70\% de nossos cidadãos têm problemas de letramento, comprometidas as habilidades de leitura e escrita. Para concluirmos esse panorama estatístico, apresentamos o Índice de Desenvolvimento da Educação Básica (Ideb), criado pelo Inep em 2007. Tal indicador (que consiste em nota de 0 a 10) é resultante do cruzamento de dados sobre o fluxo escolar (aprovação) e as médias das avaliações promovidas pelo Inep, Saeb (Sistema de Avaliação da Educação Básica), que se aplicam aos estados, em nível nacional, e a Prova Brasil, para os municípios. Em 2015 (última estatística até março de 2018), nossas escolas apresentaram os seguintes resultados:

- $\quad$ Anos Iniciais do Ensino Fundamental - estaduais: 5,8; municipais: 4,9; privadas: 6,8.

- $\quad$ Anos Finais do Ensino Fundamental - estaduais: 4,5; municipais: 3,9; privadas: 6,1.

- $\quad$ Ensino Médio - instituições estaduais: 3,5; instituições privadas: 5,3 (BRASIL, 2016)

Notemos que, uma vez mais, as estatísticas confirmam a distância entre os resultados da escola pública e os da escola privada que, embora tenham apresentado queda, se aproximam do desempenho de instituições de países desenvolvidos da OCDE (Organização para Cooperação e Desenvolvimento Econômico). Vale ressaltar a necessidade de problematizarmos tais números, sobretudo pela complexa realidade educacional do Brasil, que revela múltiplas singularidades e contextos não contemplados pelas avaliações. Os resultados de uma escola a descrevem apenas sob certa ótica e racionalidade que caracterizam aquele indicador em larga escala. Se, por um lado, 
essa política pode auxiliar uma instituição mal avaliada, inclusive destinando verbas públicas que venham a socorrê-la, por outro, submetem-na a uma condição humilhante que pode minar a autoestima e a confiança de seus atores sociais. O Ideb, com seus limites, também nos indica os pífios desempenhos da escola pública nacional, dentre os quais se destaca, negativamente, o Ensino Médio, ponto de chegada de pelo menos 14 anos da Educação Básica (se desconsiderarmos a Creche), o que interessa bastante aos empresários do setor educacional. O fato de constituírem apenas indicadores, recortes estatísticos, todavia, não implica desautorizarmos os dados aqui enumerados, sobretudo pela isenção dos órgãos que os coletaram. Recomendamos apenas que sejam analisados com cuidado, considerando em especial as condições de produção dos mesmos, como políticas públicas de avaliação.

Em uma abordagem que se volta para vinte e cinco séculos, Dewey (1959) afirmara que, na Atenas de Sócrates, guardadas as proporções com nossos dias, já havia a tríade: Estado - Escola - Sociedade. Naquele contexto político escravista, somente $10 \%$ da população eram cidadãos a quem cabia a escolaridade, conduzida por mestres como os sofistas, na ágora, Platão e sua Academia, Aristóteles e o Liceu (ABRÃO; COSCODAI, 2005). Uma asserção deweyana central para a nossa análise acerca do secular desinteresse discente é o fato de que, nesse contexto histórico, houve a separação pedagógica entre teoria e prática, valorizando-se a primeira, ao passo que as atividades manuais não tinham prestígio; noutras palavras, a placa na escola de Platão, em que se lia: "Só entre se souber geometria”, nos revela a escolha pela episteme como vivência intelectual superior, cabível apenas ao cidadão ateniense. Outras experiências seriam relegadas a planos inferiores, como a expressão artística, as aprendizagens práticas, dentre aqueles saberes "pouco nobres”. Infelizmente, muito embora o formato de escola que hoje presenciamos tenha nascido com a modernidade e o liberalismo (PATTO, 1999), herdamos, em boa medida, o ideário segregacionista grego. Essa separação entre trabalhos manuais (para os escravos, artesãos, estrangeiros, mulheres) e a teoria (para o cidadão ateniense), segundo a percepção deweyana, teria resultado em uma deformação da experiência (o que nos passa, dimensão do existir), com consequências nefastas para a escolaridade; o conhecimento se tornaria aristocrático, formal, distante do vivido. (DEWEY, 1958)

De que maneira esse ideário teria nos alcançado? No contexto brasileiro, viabilizado pela ação dos jesuítas, que aqui se instalaram em 1549, apresentando como características gerais de sua doutrina pedagógica o tomismo (apropriação de Aristóteles, feita por São Tomás de Aquino), o humanismo, a autoridade do texto bíblico, a memorização e o maniqueísmo, dentre outros preceitos da ratio studiorum. Para o desinteresse ou dificuldade de aprendizagem das crianças, o tratamento comum era a vara de marmelo e outros açoites como a "palmatória de curupira" (ROMANELLI, 2010). Com relação à escravatura, vale lembrar que as fazendas jesuíticas tornaram-se um empreendimento muito rentável da colônia, especialmente por se utilizarem da mão de 
obra escrava: em 1757, havia 740 negros cativos nas propriedades jesuíticas (LEITE, 1950). Quando a coroa portuguesa percebeu que os padres não atendiam mais aos interesses estatais, expulsou-os pelas mãos do Marquês de Pombal, em 1759. Notemos que o amálgama triádico Estado - Escola - Sociedade revelara-se essencial para que o projeto moderno educacional se realizasse. Os religiosos, ao levarem adiante um projeto humanista, distante das demandas novas e iluministas da modernidade, contrariavam os interesses do governo e o modelo econômico capitalista comercial, que se transformava em industrial. Apesar de banidos, sua tradição pedagógica seguiu adiante, com escolas primárias e médias administradas por religiosos, além dos seminários. Verificarmos o quanto de Atenas chegou aos nossos dias constitui-se, portanto, um exercício instigante, em especial, se pensarmos na história da instituição escolar e das concepções pedagógicas. Naqueles dias pombalinos, víamos já bemplantadas as raízes de um contexto que se denominou fracasso escolar. Estava posta a divisão entre a escola particular e a pública, no contexto da educação básica. A crise instala-se quando as crianças das classes trabalhadoras e rurais dirigem-se à escola estatal. Novidades como o subsídio literário (primeiro salário para o docente), aulas régias, disciplinas isoladas, laicização, dentre outros aspectos, não escondiam o fato de que toda política sempre revela a atitude de um legislador público que não consegue fazer nada além de representar sua própria classe social e respectivos interesses. A educação jesuítica teve fundamental papel com relação a fomentar um perfil de família patriarcal brasileira, escravista e latifundiário, em certa medida, uma caricatura da aristocracia europeia. (ROMANELLI, 2010)

Muito embora os padres tenham sido "expulsos” com a vinda do Marquês de Pombal, até hoje mantêm inquebrantáveis os laços pedagógicos com o ensino tradicional e privado; instituições católicas (e também protestantes) são em geral expoentes em matéria de qualidade educacional, analisada sob a ótica sobretudo produtivista. A instrução formal, escolarizada, no período colonial e imperial, cabia somente a alguns homens da aristocracia, não poderiam ser primogênitos, pois estes deveriam administrar os bens do clã, nem mulheres. Negros eram proibidos de frequentar instituições escolares (apesar de receberem catequese nas fazendas jesuíticas), o que perdurou até a Reforma de Leôncio de Carvalho, em 1879, que admitia matrícula de escravos. Dentre tantas consequências, nem sempre negativas, daqueles 210 anos de atuação da Companhia de Jesus, a ideia de inferiorização do negro, do índio (e da mulher), parece-nos ser o legado mais perverso, vindo a fundamentar a eugenia. Com a industrialização intensa no fim do século XIX e começo do século XX, os negros, então libertos (sem preparo profissional para as demandas industriais), viram os postos de trabalho serem ocupados pelos imigrantes europeus, que deveriam também promover o branqueamento do povo brasileiro (FERNANDES, 1966).

Ainda no período imperial, o que Romanelli (2010) denomina de pequena burguesia brasileira vivia um paradoxo: ligava-se à aristocracia rural, mas bebia nos ideais 
Relações entre o esvaziamento da função simbólica e o desinteresse discente pelas rotinas escolares

iluministas, que contestavam os valores feudais. Tal tensão iria se aprofundar, afastando definitivamente tais elites sociais, a burguesia iria vencer; tal como se observou em três históricos eventos: a abolição da escravatura, a proclamação da república e, mais adiante, o fortalecimento do capitalismo industrial.

No começo do século XIX, com a vinda da Família Real, em 1808, trazendo as universidades para o Brasil, observamos que o poder central gerenciava os destinos das universidades, cabendo às províncias o mesmo com relação ao ensino primário e o profissional. Nesse momento, o governo financiava as escolas públicas - os liceus, com professores sem habilitação. A aristocracia rural e a burguesia noviça - jornalistas, comerciantes, mineradores, etc. - investiam nas escolas particulares, com destaque às católicas. As elites brasileiras devem muito à vinda de D. João, sem o que não teriam condições de sua ascensão, em meados do século XIX. (ROMANELLI, 2010)

A República, com a Constituição Federal de 1891, aprofundou as diferenças entre as escolas pública e privada, sobretudo com o dualismo entre educação profissional e superior. Para a classe dominante, escolas secundárias e universidades; para a classe trabalhadora, escolas primárias e profissionalizantes. Não se construíam instituições à altura das novas demandas, do ritmo que se impunha, desenhando-se um profundo descompasso entre o desenvolvimento econômico e o sistema de ensino. (CUNHA, 1991)

Em 1930, tempos de Getúlio Vargas, vemos crescer a exigência por mão de obra técnica. A escola básica brasileira constitui a imagem da estratificação social. Os escolanovistas formulam, pela primeira vez, o problema do fracasso da escola pública, deslocando para o professor o foco da questão, com o "Manifesto dos Pioneiros da Educação Nova”, de 1932, liderado por Fernando de Azevedo e Anísio Teixeira, dentre outros intelectuais ligados à educação. (ROMANELLI, 2010)

Das hipóteses que, nessa época, tentam explicar a dificuldade das crianças em obter resultados satisfatórios, a primeira foi a inferioridade racial advinda dos tempos coloniais e imperiais: negros, índios e mestiços seriam considerados inferiores. A eugenia no país de Monteiro Lobato revela-se com Jeca Tatu, em 1920, encarnação literária do caboclo preguiçoso, improdutivo e decadente, em consonância com o ideário antropológico evolucionista do século XIX. (PATTO, 1999)

De modo gradativo, a teoria racista, cujo auge ocorreu entre 1850 e 1930, cede lugar ao psicologismo. Testes de Ralph Tyler e Claparède procuram aferir e explicar a incapacidade das crianças em aprender. Temos aqui a parceria, senão o governo da Psicologia, determinando os rumos da Pedagogia, anos de 1930. Concomitante a tal contexto, surge também a hipótese da carência cultural: crianças pobres teriam, por sua condição de miserabilidade, culturas inferiores à escolar, logo não conseguiriam acompanhar o aprendizado. Esta abordagem veio a superar as hipóteses psicométrica e a racial. (CUNHA, 1991) 
Consideramos importante, neste ensaio, apresentar tais explicações acerca do insucesso escolar, sobretudo porque, em seu descalabro, também contribuíram - e cremos que ainda hoje o fazem - para aprofundar e realimentar a derrota da educação pública.

Outro aspecto a ser considerado nesta análise, parece-nos, é o fato de não ter havido acordo entre os trabalhadores e as classes patronais (fins do século XIX e começo do século $\mathrm{XX}$ ), ocasião em que a indústria promovia profundas transformações sociais no Brasil, (acordos que houve na Europa) o que atrasou sobremaneira os destinos da educação pública. (CUNHA, 1991)

Uma causa que, neste texto, elencamos como central para a crise escolar, diz respeito à marginalização cultural que a escola tem promovido com relação aos estudantes que a buscam: as condições históricas e socioeconômicas das crianças contribuem para a sua própria exclusão. A escola pública recebeu, no início republicano, estudantes cujas experiências culturais não se coadunavam com as propostas pedagógicas levadas adiante, com isso, passou a atuar como mecanismo de marginalização cultural (ROMANELLI, 2010). Tal asserção coincide com a hipótese de Bourdieu: a instituição educativa constitui, desde sempre, um instrumento de reprodução, perpetuação e legitimação das classes sociais. Aqui, vale destacar o papel da violência simbólica descrita pelo sociólogo francês como formadora do habitus - sistema específico de valores e de disposições para agir e sentir que caracterizam e situam cada grupo na estrutura social (BOURDIEU, 1998). As elites delegariam cada vez mais poder de seleção à escola, pela aparente neutralidade que apresenta em seus ritos cotidianos. Esta, também por violência simbólica, impõe dissimuladamente um arbitrário cultural elitista, que se apresenta com feições de cultura universal. A criança cujo habitus familiar reúna traços como erudição, elegância ao falar, escrever e comportar-se, disciplina, curiosidade, dentre outros aspectos, terá um destino educacional mais exitoso, aproximando-se do que a autoridade pedagógica professa como socialmente legítimo e de valor; quanto mais se afastarem desses valores, maior a segregação sofrida pelos pequenos, inclusive em termos de avaliação; maiores as chances de naufragarem no percurso da formação básica. (BOURDIEU; PASSERON, 1975).

Para Cunha (1991), o contexto escolar também se configura como produtor de marginalização cultural: fora da escola, as culturas são apenas diferentes; é ela que transforma diferença em marginalidade.

A influência do pensamento durkheimiano na pedagogia brasileira parece-nos outro fator marcante, quando analisamos as causas da crise educacional. Lourenço Filho traduziu "Educação e Sociologia”, em 1939; um sucesso em cursos normais do Rio de Janeiro e Recife. Se pensarmos em tal ideário, eminentemente organicista, que sempre propusera, grosso modo, a preparação física, moral, intelectual da criança/ adolescente para as futuras demandas da sociedade, inclusive, subordinando a Pedagogia 
à Psicologia (DURKHEIM, 1978), veremos que tal perspectiva sociológico-educativa também se insere no complexo conjunto de fatores que levam ao desinteresse pela experiência escolar. Isto afirmamos pelo fato de que tal visão pedagógica considera o aluno um vir a ser, o que nos parece não respeitar sua condição presente, de ator social, sujeito de direitos.

O percurso das abordagens pedagógicas hegemônicas, desde a ratio studiorum jesuítica até a pedagogia tecnico-produtivista, que vem a suplantar gradativamente o escolanovismo nos anos de 1960 e persiste até nossos dias (SAVIANI, 2008), também se configura, salvo engano, resposta à questão do desinteresse discente pelos estudos. Tal perspectiva que, grosso modo, prima pelo acúmulo máximo de informação, a um custo o mais baixo possível, em menor tempo (SAVIANI, 2008), consolidou-se nos tempos de ditadura militar, além de alinhar-se à tradicional concepção durkheimiana de escola: preparação do discente para o mercado. Esse modo de racionalidade instrumental pedagógica reinventa-se a todo instante, na contemporaneidade.

Florestan Fernandes (1966) enumerou o que seriam os fatores do insucesso escolar: herança escravista, colonialismo, imperialismo, urbanização, industrialização, estratificação social. Tais causas, cremos sintetizarem, por ora, esta análise. Conforme já enunciamos, pretendemos discorrer, a seguir, sobre aspectos da comunicação no contexto didático, com destaque para os signos, em geral, que engendram os saberes pedagógicos, na hipótese de que se constituem, em sua degeneração simbólica, como um fator de importância central, dentre as causas relativas ao desinteresse dos estudantes pelas matérias ensinadas.

\section{Asserções sobre linguagem e experiência}

Antes de adentrarmos as questões concernentes ao símbolo, conforme a compreensão pragmatista, vemos a necessidade de analisar como essa filosofia descreve a linguagem. Dewey a entendia em um sentido mais amplo do que o comum, revelando-se nos enunciados orais e escritos, assim como os gestos, ritos, cerimônias, monumentos, produções artísticas e industriais, etc. Itens de consumo, tais como um aparelho televisivo ou um calçado, seriam realizações da linguagem; que se revela fator essencial à experiência dos seres em geral. Os objetos criados pela cultura apresentam uma significação partilhada pelos membros de uma sociedade, operando também como signos. Um aspecto da linguagem que a torna fundamental à experiência reside no fato de que ela não somente transmite conteúdos de culturas não orgânicos (pactuados socialmente), como se constitui em um modo de comportamento biológico, que se realiza em continuidade e atendendo a imperativos naturais, muito embora exija dos indivíduos a adoção do ponto de vista dos outros, abandonando a perspectiva particular que, na vida orgânica, tem maior destaque. A linguagem apresenta como referência primeira o(s) outro(s), com quem se estabelece a comunicação. Vemos nisto implicações epistemológicas: o símbolo como um operador central do pensamento 
reflexivo; éticas: a necessidade de se considerar o outro na construção dos significados da experiência; políticas: a comunicação torna-se um bem comum, fator agregador; além de aspectos gnosiológicos, estéticos, etc. A linguagem faz com que todos esses aspectos se coadunem, de tal sorte que não se separem, a não ser por finalidade didática. Dewey ressaltou que o sentido de um símbolo convencional não se apresenta, em si mesmo, convencional, uma vez que se firma por acordos coletivos que nasceram de atividades existenciais e sinalizam para consequências no vivido. A linguagem torna-se um meio comunicativo, partilhando sentidos comuns, sem a qual não há possibilidade de experiência (DEWEY, 1950), que se constitui, grosso modo, em tudo o que nos passa e atinge, bem como naquilo que se transforma por nossa ação no mundo, em um meio físico-cultural. A linguagem fundamenta a capacidade lógica, que orienta o pensamento reflexivo. O que legitima tais aspectos é o acordo na ação, um consentimento comum que confere à convenção a índole de mediar e comunicar o sentido, promovendo também a possibilidade de que as partes envolvidas no processo comunicativo partilhem respostas ativas e de que se responsabilizarem pelas consequências. (RORTY, 2000)

\section{A perda de representatividade simbólica}

A baixa qualidade do ensino ligada ao despreparo dos educadores tem como uma das causas a não reflexão, da parte deles, sobre a natureza corrompida dos códigos inerentes aos discursos pedagógicos, dentre outros motivos. O termo "corrompida” não apresenta, aqui, nenhum juízo de valor; aproxima-se mais do significado utilizado pela informática, tal como em: “arquivo corrompido”; na verdade, refere-se à perda de representatividade que os símbolos (com que se estruturam os códigos) sofrem, infinitamente afastados da experiência de viver dos alunos e professores. Tais sinais apresentam o que Peirce (1977) considerou degeneração sígnica; noutras palavras, a incapacidade de cumprir genuinamente a função comunicativa do símbolo: estar no lugar de um objeto capaz de representar uma classe de seres.

A perda em questão compromete evidentemente o processo ensino-aprendizagem, posto que ele se estrutura pela linguagem em suas mais diversas realizações. Dewey fora testemunha desse contexto, denunciando o desinteresse discente pelo aprendizado:

Quantos estudantes, por exemplo, não chegaram a ser insensíveis às ideias e quantos não perderam o ímpeto para aprender, dado o modo com que experimentaram a instrução? Quantos não adquiriram capacidades especiais por meio de um adestramento automático, de modo que ficou limitada sua faculdade de julgar e sua capacidade de atuar inteligentemente nas situações novas? Quantos não chegaram a associar o processo de aprender com o enfadamento e o cansaço? (DEWEY, 1958, p. 24)

Suas indagações revelam em que medida a instituição escolar pode contribuir 
para a insensibilidade às ideias, o desinteresse, o automatismo, a incapacidade moral (formulação de juízos) e lógica, o enfadamento com o aprendizado, por parte dos alunos. Ratificamos a asserção de que a degeneração da linguagem atua, nesse sentido, por apresentar a instrução de modo racionalista, distante dos enunciados que fazem sentido para o discente.

\section{Por uma linguagem simbólica genuína}

Antes de tratarmos especificamente dos processos que comprometem a atuação do símbolo na relação pedagógica, convém que definamos signo, sobre o qual Peirce declarou:

\footnotetext{
Um signo, ou representâmen, é aquilo que, sob certo aspecto ou modo, representa algo para alguém. Dirige-se a alguém, isto é, cria, na mente dessa pessoa, um signo equivalente, ou talvez um signo mais desenvolvido. (PEIRCE, 1977, p. 46)
}

A descrição peirceana de signo, conforme verificamos no fragmento, enumera três correlatos: o representâmen, o objeto ("algo") e o interpretante ("signo equivalente"). O primeiro, sinônimo de signo, cumpre a função de estar no lugar de um objeto da realidade, sobre o qual enuncia significados (interpretantes). Da relação do representâmen com objeto, temos a tríade mais famosa de Peirce: ícone / índice / símbolo. O ícone é um signo que se parece estruturalmente com aquilo que representa, sendo apenas uma possibilidade de fazê-lo. Exemplo: foto do Corcovado, no Rio de Janeiro; o índice, diferentemente, constitui um signo de existência, garantidor de que o objeto seja representado. Exemplo: a sombra de nosso corpo que praticamente desaparece ao meio dia, representando tal horário. O símbolo constitui um signo, cujo objeto deve representar uma classe de seres, o que confere à representação caráter de lei pactuada socialmente. Exemplo de símbolo: a palavra 'mãe'.

Para Peirce, o símbolo genuíno deverá denotar um contexto individual e um caráter geral. O filósofo fornece-nos o exemplo de um pai que, proferindo para o filho a palavra "balão", aponta para o objeto no céu. Toda vez que pensar no termo "balão", o filho terá em sua discursividade um signo genuíno, dado que recobrará o ícone mental do objeto e o índice, caracterizado pelo braço e mão do pai, apontando o que fora representado. $\mathrm{O}$ aspecto icônico conferiu generalidade ao objeto e o indicial, a garantia de singularidade. Imaginemos que uma criança jamais tenha visto um balão e indague ao pai sobre o que seria tal objeto e a resposta seja: "É algo como uma grande bolha de sabão"; o que o pequeno teria para o termo "balão" seria um exemplo de símbolo degenerado, posto que disporia de um ícone mental, que apenas enuncia a possibilidade de representação, sem o aspecto indicial, que conecta o signo à existência, garantindo a referencialidade. Há, para Peirce, dois tipos de símbolos degenerados: singular - cujo objeto é um ente individual, denotando somente os 
caracteres daquela particularidade $\neg-$ e abstrato - cujo objeto único seria um caráter geral. (PEIRCE, 1977, p. 71)

Imaginamos como símbolo degenerado o nome de uma flor cuja espécie somente apresentasse um único indivíduo. Tal nome seria, se não erramos, um símbolo degenerado, na medida em que o interpretante sígnico corresponderia apenas aos caracteres daquele indivíduo, não representando um caráter geral. Um ente cujos traços não reúnem condições de generalização. O exemplo de degeneração sígnica fornecido por Peirce (o termo "balão”, sem a experiência colateral) ilustra bem o símbolo abstrato, uma vez que o objeto fora apresentado à criança apenas quanto ao caráter geral, abstrato e, por que não afirmarmos, formal. Estamos certos de que a degeneração simbólica de tipo abstrato caracteriza, em grande medida, os signos dos conteúdos escolares, sobretudo porque são transmitidos arbitrariamente, sem índices que estabeleçam as relações entre as matérias e o mundo vivido dos estudantes.

Não há pensamento sem linguagem, eis um consenso entre tais autores. Cumpre, portanto, a todos os envolvidos na enunciação dos códigos inerentes aos conteúdos disciplinares, a tarefa de perseguirem uma linguagem assentada em símbolos genuínos - o que supõe a presença de signos indiciais a eles relativos, garantidores de que os elementos de existência sejam reapresentados à mente interpretante (PEIRCE, 1977). Não havendo a operatividade dos índices, o que temos é a degeneração do símbolo. Entenda-se esta degeneração como a incapacidade de garantir a existência de um objeto. Exemplo da disciplina de Geografia: o conceito universal de Trópico de Capricórnio, ensinado no quarto ano do Ensino Fundamental. Se o professor não fizer um grande esforço para apresentar índices genuínos, que concorram para a construção de tal símbolo, as crianças terão apenas mais um dado morto a decorarem. Um exemplo de símbolo genuíno: o conceito de coração, na disciplina de Ciências Naturais, trabalhado de tal modo que o professor utilize procedimentos indiciais, como pedir que as crianças sintam o próprio pulso.

A linguagem, para Dewey, teria três grandes propósitos que a caracterizam: fazer com que, impulsionada pelo desejo cognitivo, a subjetividade de quem se expressa atue na experiência do outro; viabilizar relações sociais mais íntimas; transmitir conscientemente o conhecimento. (DEWEY, 1958) Para que haja esta tríplice transmissão de experiência proposta, obviamente que a textura dos códigos deverá primar por símbolos genuínos. Isso propiciará a recriação da experiência de viver, no ambiente pedagógico: o encanto com o conhecimento significará a possibilidade de uma nova narrativa. Uma fórmula matemática, maquete geológica, pintura em guache, constituir-se-ão atualizações do viver. A rotina pedagógica, como um todo, o será: em vez de preparar para a vida, tornar-se-á a própria vida. Eis o salto a que todo aluno deverá aspirar, a plenitude de suas potencialidades estéticas, éticas, afetivas, políticas e lógicas. (PAGNI, 2010) 
Relações entre o esvaziamento da função simbólica e o desinteresse discente pelas rotinas escolares

Apresentamos então aos profissionais de educação um desafio espinhoso: empreenderem uma reflexão sobre a natureza dos signos que engendram os seus discursos e conteúdos pedagógicos, fazendo a si mesmos a pergunta: até que ponto tais enunciados dizem respeito à experiência de viver, minha e dos alunos? Em que medida esta fórmula, conceito ou representação, que pretendo ensinar ou partilhar, tem lastro na existência? Quanto mais distante dela se encontrar o conteúdo, maior a perda da capacidade de reapresentar à mente interpretante os objetos do mundo, consequentemente, maior será o desinteresse dos alunos. O sucesso do método alfabetizador de Freire (1980), tendo como carro chefe a palavra geradora, constitui prova notória da importância de se considerar, nas rotinas pedagógicas, a experiência discente de viver nas rotinas pedagógicas.

\section{Considerações Finais}

Ao concluirmos este escrito, retomamos aqui algumas asserções obtidas no percurso: a crise educacional brasileira, cujas características consolidam-se no início do século XIX e ainda hoje se revelam, com a indústria do fracasso escolar, é resultante de um complexo arranjo causal - passado escravagista, colonialismo, eugenia, abordagens pedagógicas ineficientes (dependentes da avaliação), gestão pública excludente, a própria instituição educativa sendo perpetuadora das diferenças sociais, industrialização do país. Além desses e outros aspectos que culminam com o insucesso da educação pública (refletido, por exemplo, nas dificuldades que a maioria dos brasileiros apresenta ao escrever e interpretar textos), apontamos o comprometimento operativo dos símbolos que engendram os códigos instrucionais, sua corrosão (perda de referencialidade) ao reapresentarem aos estudantes os objetos do mundo vivido, gerando o desinteresse destes pelas rotinas escolares e o consequente naufrágio da escolaridade. Obtivemos asserções do que pode ser um novo contexto para a relação entre educando e educador. Vimos que as abordagens de Dewey, com o resgate da experiência no ambiente educativo, sinalizariam nesse sentido, o que não significa afirmarmos uma esperança salvacionista, até porque se trata de uma perspectiva pedagógica dificilmente levada a termo.

A degeneração simbólica que aparece nos primórdios da educação escolar, orientada por ideais aristocráticos, atende a interesses políticos, desde os tempos greco-latinos: saberes práticos diziam respeito a escravos e outros indivíduos que não fossem cidadãos; ao estes nobres, cabia o conhecimento teórico, formal, enfim, a verdade epistêmica, ensinada na Academia grega ou, vinte e cinco séculos depois, no Colégio Dom Pedro II. Na Atenas escravocrata, tivemos a origem da dicotomia teoria e prática, promovendo a degeneração simbólica, segundo Dewey (1959), à medida que muitos conceitos formais não guardavam nexo com a experiência, iniciando uma marcha epistemológica hierarquizante dos saberes que nos atinge até os dias atuais; o eidos platônico, com suas identidades fixas e eternas, ilustra de forma ímpar o esvaziamento da função 
de referência dos símbolos, que não contariam com ícones e índices garantidores de objetos situados na existência. Vejamos um exemplo matemático de Hiparco de Niceia (180-125 a.C.): Em trigonometria, a função seno é uma função periódica e seu período é $2 \pi$, eis a expressão: função $f(x)=\operatorname{sen} x$. Note-se que não há como tal enunciado se ancorar em signos icônicos e indiciais, trata-se de um conteúdo absolutamente formal, sem objeto(s) de existência para o signo matemático. Sua demonstração somente é possível de forma lógica e dedutiva. A degeneração, desse modo, passa a promover a cunhagem de marcas de distinção social, pela dificuldade que temos em construir sistemas conceituais formalistas. O discípulo na ágora grega, todavia, revelava condições para adquiri-los e diferenciar-se como indivíduo, empoderando-se ao cortejar as fórmulas do espírito.

Com os jesuítas não foi diferente, seu projeto humanista e neoclássico legitimou e perpetuou aqueles saberes destinados aos sábios, alicerçados no aristotelismo tomista. A educação empreendida pelos padres traduzia os interesses da aristocracia colonial. Símbolos de erudição, como o ensino de latim, filosofia, linguística, biologia, etc., moedas sociais de grande quilate, ainda hoje observamos brilhar nos juízos da magistratura, da medicina e de tantas outras instituições discursivas. "Et ipsa scientia potestas est" "2, eis uma proposição que tem governado os destinos da escolaridade.

No Brasil imperial, as ideias iluministas prevaleceriam finalmente sobre as concepções escravocratas, contudo, o abismo que se abria por ocasião do surgimento da universidade, uma vez mais, ilustrava aquela separação fundante entre o conhecimento formal e o saber prático. O primeiro caberia aos filhos das elites que se consolidavam - comerciantes, jornalistas, industriais, etc. -; o segundo seria destinado aos rebentos das classes populares. A escola pública, com os liceus e docentes mal preparados, herdara também aquela visão de ensino tradicional, embora voltada à formação profissionalizante. As instituições privadas, destaque às religiosas, continuavam vendendo às elites o conhecimento assentado em degeneração simbólica, transformando-o, contudo, em marcas de distinção social, conforme já afirmamos. Aprenderia quem pudesse pagar e esforçar-se muito para adquirir os tesouros da aristocracia secular, superando o desinteresse, motivando-se quem sabe pela ânsia de ascensão social. Poderíamos, aqui, como fizemos com a trigonometria, fornecer enunciados simbólicos das mais diversas áreas do conhecimento, a serem apropriados pela Educação Básica, como na Física, Gramática, Zoologia, e assim por diante, o que tornaria a reflexão um tanto prolixa. Reafirmamos que o percurso histórico da instituição escolar consolidou o logocentrismo, tendo na modernidade a perpetuação de discursos didáticos que, necessariamente, levariam ao desinteresse, posto que ele teria se revelado um problema contornável em relação às escolas elitistas. Se analisarmos cuidadosamente, um aspecto ainda mais perverso de tal contexto tem se revelado: o desinteresse pelo

2 Tradução: "Saber é poder" - proposição que tem sido proferida por toda a história do pensamento, desde Aristóteles, Platão, na antiguidade; Francis Bacon, na modernidade; Michel Foucault, no presente. 
ensino lança à própria sorte gerações inteiras de estudantes oriundos das classes menos privilegiadas, diminuindo, em grande escala, suas chances já mínimas de mobilidade social. Inferimos disso que a indiferença dos pobres pela aprendizagem torna-se um benefício para aqueles matriculados nas instituições privadas, quando se lançam ao mercado de trabalho.

Na República, assistimos ao aprofundamento do dualismo entre educação profissional e superior. Uma prova inequívoca de nossa hipótese para o insucesso da instituição educativa, a verificamos com o imenso descompasso assinalado por Cunha (1991) entre o desenvolvimento econômico e o sistema de ensino, que se constituía herdeiro de uma concepção curricular ad doctrinam, reafirmamos, em detrimento de um saber que pudesse expressar, em símbolos genuínos, o vivido e, como tal, o desenvolvimento econômico. Alunos que assistiam à industrialização do país encontravam pouco nexo entre ela e o que aprendiam em sala de aula; como resultado, uma vez mais presenciava-se o desinteresse e a dificuldade com a aprendizagem.

Uma ressalva importante: de modo algum negamos o valor do conhecimento universal adquirido e acumulado, como os legados de Tales, Euclides, Descartes, Camões e tantos outros titãs da cultura universal. O que procuramos enunciar neste trabalho é que a didatização desses sistemas conceituais dificilmente escapará da degeneração simbólica, conforme a descrevemos. Eis um secular drama pedagógico: definirmos o que deve ser objeto de transposição didática - conteúdos do discurso científico que se tornem escolares, nos termos da instituição educativa contemporânea. Também alertamos serem certos saberes absolutamente necessários à formação discente, cujos objetos são produtos da própria linguagem, não havendo outro modo de representálos senão pela degeneração simbólica. Um exemplo para o que afirmamos vem a ser a operatividade dos conceitos de análise sintática, sobretudo pelo que impactam na expressão verbal de cada indivíduo. Concluímos, então, que a tessitura do pensamento e da linguagem conta, evidentemente, com inferências alicerçadas em certa degeneração simbólica, contudo, esta não pode ser o matiz predominante dos signos, enunciados, conceitos, ações inerentes a um núcleo de instrução, parte de uma proposta pedagógica.

O comprometimento da aprendizagem tem apresentado consequências econômicas, sociais, políticas que, em síntese, negam a cidadania a muitos que buscaram os serviços da educação pública. Ratificamos o desafio a ser enfrentado por todos os que se lançam à carreira na docência: repensarmos nossa ação profissional a partir do que aprendemos com o passado, reescrevendo, na medida do possível, os códigos dos conteúdos disciplinares assentados em símbolos genuínos, legitimados na experiência - aventura de viver. 


\section{Referências}

ABRÃO, B.; COSCODAI, M. História da filosofia. São Paulo: Sapienza Editora, 2005.

BOURDIEU, P. Escritos de educação. Petrópolis: Vozes, 1998.

BOURDIEU, P.; PASSERON, J. C. A reprodução. Elementos para uma teoria do sistema de ensino. Rio de Janeiro: Francisco Alves, 1975.

BRASIL. MEC. Ministério da Educação. INEP - Instituto Nacional de Estudos e Pesquisas Educacionais Anísio Teixeira. Censo Escolar da Educação Básica de 2014. Brasília, 2014.

BRASIL. MEC. Ministério da Educação. INEP - Instituto Nacional de Estudos e Pesquisas Educacionais Anísio Teixeira. Censo Escolar da Educação Básica de 2016. Brasília, 2017.

BRASIL. Congresso Nacional. Lei $N^{\circ}$ 10.172, de 9 de janeiro de 2001. Aprova o Plano Nacional de Educação e dá outras providências. Dário Oficial da República Federativa do Brasil. Brasília, 09/01/2001.

CUNHA, L. A. Educação e desenvolvimento social no Brasil. Rio de Janeiro: Francisco Alves, 1991.

CUNHA, M. V. Educador e filósofo da democracia. In: REGO, T. C. (Org.). História da Pedagogia. São Paulo: Editora Segmento, 2010, p. 32-43.

DEWEY, J. Como pensamos. São Paulo: Companhia Editora Nacional, 1959. Experiencia y educación. Buenos Aires: Losada, 1958. . Lógica, teoria de la investigacion. México: Fondo de Cultura Econômica, 1950.

DURKHEIM, E. Educação e Sociologia. São Paulo: Melhoramentos, 1978.

FAVERO, A. Altair. Redescrição de mundo e educação. Tese de Doutorado. Porto Alegre: UFRGS, 2006.

FERNANDES, F. Educação e Sociedade no Brasil. São Paulo: Dominus, Ed. Universidade de São Paulo, 1966.

FREIRE, P. Conscientização, teoria e prática da liberdade: uma introdução ao pensamento de Paulo Freire. São Paulo: Moraes, 1980. 
FREITAS, L. C. Crítica da organização do trabalho pedagógico e da didática. Campinas: Papirus, 1995.

IBGE. Fundação Instituto Brasileiro de Geografia E Estatística. PNAD 2011. Pesquisa Nacional por Amostra de Domicílios. Censo Escolar. Rio de Janeiro, 2011. . PNAD 2014. Pesquisa Nacional por Amostra de Domicílios. Censo Escolar. Rio de Janeiro, 2014. . PNAD 2016. Pesquisa Nacional por Amostra de Domicílios. Censo Escolar. Rio de Janeiro, 2017.

LEITE, S. S. F. História da Companhia de Jesus. Rio de Janeiro: Instituto Nacional do Livro, 1950.

LIBÂNEO, J. C.; OLIVEIRA, J. F.; TOSCHI, M. S. (org). Educação escolar: políticas, estrutura e organização. São Paulo: Cortez, 2010.

LIBÂNEO, J. C. Didática. São Paulo: Cortez, 2012.

LUCKESI, C. C. Avaliação da aprendizagem escolar: estudos e proposições. São Paulo: Cortez, 2008.

PAGNI, P. A. Escola, estética e ética. In: REGO, T. C. (Org.). Historia da Pedagogia. São Paulo: Editora Segmento, 2010, p. 32-43.

PATTO, M. H. S. A produção do fracasso escolar: histórias de submissão e rebeldia. São Paulo: Casa do Psicólogo, 1999.

PEIRCE, C. S. Semiótica. São Paulo: Editora Perspectiva, 1977.

QUINTANEIRO, T.; BARBOSA, M. L. O.; OLIVEIRA, M. G. M. Um toque de clássicos. Marx / Dürkheim / Weber. Belo Horizonte: Editora UFMG, 2002.

ROMANELLI, O. O. História da Educação no Brasil. Petrópolis, RJ: Vozes, 2010. RORTY, Richard. A filosofia e espelho da natureza. Rio de Janeiro: Relume-Dumará, 1995.

. Pragmatismo: a filosofia da criação e da mudança. Belo Horizonte: Editora UFMG, 2000.

SAVIANI, D. História das ideias pedagógicas. Campinas: Autores Associados, 2008. 
UNESCO. United Nations Educational, Scientific and Cultural Organization. Education for All Global Monitoring Report. Library of Congress Cataloging in Publication Data: Paris, 2015.

Recebido em: 18/02/2018

Aprovado em: 17/12/2018 